\title{
A interculturalidade no ensino-aprendizagem de espanhol como língua estrangeira: os gêneros como mediadores culturais.
}

\author{
Lucila Carneiro Guadelupe \\ Universidade Federal de Juiz de Fora (UFJF) \\ Marta Cristina da Silva \\ Universidade Federal de Juiz de Fora (UFJF)
}

\begin{abstract}
Resumo
Este trabalho é parte de uma pesquisa em andamento voltada aos gêneros como mediadores (inter) culturais no ensino de Espanhol/Língua Estrangeira. Seu objetivo é analisar um material aprovado pelo Programa Nacional do Livro Didático. Resultados revelam que os gêneros nem sempre são adequadamente usados em termos de uma abordagem intercultural.

Palavras Chave: interculturalidade, livro didático, espanhol/língua estrangeira.

Abstract

This paper is part of ongoing research on genres as (inter)cultural mediators in the teaching of Spanish as a foreign language. It aims at analyzing a textbook which was evaluated by a national program in Brazil. Results show that genres are not always appropriately used in terms of an intercultural approach.
\end{abstract}

Keywords: interculturality, textbook, Spanish/foreign language.

\section{INTRODUÇÃO}

Nos últimos anos, no Brasil, estamos vivenciando um período de mudanças relacionadas ao ensino de Espanhol/Língua Estrangeira. Essas mudanças estão ligadas a novas diretrizes propostas em documentos oficiais, com a publicação dos Parâmetros Curriculares Nacionais - PCN/1999; PCN+/2002 e Orientações Curriculares para o Ensino Médio (OCEM/2006), além da sanção da Lei 11.161 (05/08/2005), que torna obrigatória a oferta da língua espanhola nas escolas públicas e privadas de Ensino Médio. No ano de 2012, depois de submetidos a uma rigorosa seleção do Programa Nacional do Livro Didático (PNLD), os manuais de língua espanhola para o Ensino Médio passaram a compor o quadro das obras aprovadas para o ensino de língua estrangeira.

É importante frisar que "todas as obras que queiram ter o privilégio de ser 
incluídas nesse programa precisam ser produzidas a partir dos documentos que orientam a educação brasileira" (PARAQUETT, 2012:390). Nessa perspectiva, cabe também a nós, enquanto professores e pesquisadores, investigarmos e avaliarmos o material didático que está sendo produzido para o ensino de nossos alunos. Segundo Paraquett (2012:389),

\begin{abstract}
Ainda há muito que se fazer, pois mesmo essas obras selecionadas apresentam alguns problemas, conforme é a permanência nos modelos comunicativistas para uma educação crítica, em vez de se privilegiar um ensino de base interculturalista, quando se propicia a reflexão do aprendiz quanto às diferenças culturais que nos constituem; ou mesmo a dificuldade de se trabalhar, sistematicamente, com gêneros textuais e tipologias de textos, exigência, hoje, na seleção de obras através do PNLD; ou, ainda, a hegemonia de países hispano-americanos, abandonando-se os mais periféricos, conforme é o caso da Guatemala ou da Bolívia, para citar apenas dois países de língua espanhola, completamente esquecido por muitos autores. Mas esses problemas poderão ser minimizados ou corrigidos, se continuarmos a estabelecer esse necessário diálogo entre pesquisa e produção de material didático.
\end{abstract}

De acordo com a visão apresentada pelos parâmetros educacionais, o modo de ensinar e aprender um novo idioma deve ser reavaliado, renovando-se os pensares e as posturas em relação ao ensino, para, assim, buscarmos alcançar a formação de cidadãos críticos e conscientes de seu lugar no mundo contemporâneo. Neste sentido, defende-se a adoção de uma perspectiva intercultural para o ensino de línguas, que tome a noção de gênero como eixo norteador.

Nossa hipótese se baseia na idéia de que um uso adequado dos gêneros do discurso, através de uma abordagem que contemple as questões culturais, em consonância com as propostas dos documentos oficiais que regem a educação brasileira, propiciaria o diálogo entre culturas, promovendo, dessa forma, maior reconhecimento e aceitação do outro e a compreensão da própria cultura por parte dos aprendizes.

Diante do exposto, apresentamos o principal questionamento que motivou esta pesquisa: como são abordados os elementos socioculturais e interculturais nos gêneros selecionados pelo livro didático de espanhol/língua estrangeira? Em outras palavras, o objetivo do nosso macroprojeto é investigar se os livros didáticos elaborados dentro das perspectivas de ensino atuais apresentam uma abordagem coerente com os pressupostos teóricos na área de gêneros e verificar como se articulam as propostas interculturais apresentadas pelos livros destinados à aprendizagem de Espanhol/Língua Estrangeira, por alunos da educação básica, no Ensino Médio, visando contribuir para a reflexão de professores e pesquisadores a respeito dessa importante agenda.

Para responder a essas perguntas, com o aporte de teorias de gêneros e de estudos 
sobre interculturalidade, nosso foco é uma coleção completa de livros didáticos para o Ensino Médio. O que apresentaremos aqui é uma breve análise, que esperamos possa ser aprofundada posteriormente.

\section{REFERENCIAL TEÓRICO}

No que diz respeito à noção de gênero, tomamos como referência básica a perspectiva dialógica de Bakhtin, segundo a qual os gêneros do discurso são "tipos relativamente estáveis de enunciado" (BAKHTIN, 1979/2010:262), estreitamente ligados às diversas esferas sociais que envolvem a atividade humana. Sendo concretos e únicos, refletem as finalidades de determinado campo da comunicação ou domínio social, através de seu conteúdo temático, estilo e construção composicional.

Para ressaltar nosso posicionamento em relação ao lugar dos gêneros do discurso nos procedimentos metodológicos para o ensino de línguas, concordamos com Pedrosa (2007), quando afirma:

Práticas discursivas comprovam que a língua cria o mundo, não o reproduz. [...] Por isso as atividades pedagógicas devem deixar explícito que estudar a língua é muito mais que vê-la como um sistema de regras, é estudá-la em seu uso dialógico com as outras práticas de uma comunidade, que se define linguística e socialmente, com sua ideologia e seus valores (PEDROSA, 2007:164).

É através do contexto social em que estão inseridos que os sujeitos podem produzir/compreender a linguagem. Como afirma Faraco, a consciência individual só se constrói na interação, dialogicamente (2001:32). As práticas sociais, por sua vez, caracterizando-se como heterogêneas, dinâmicas e variáveis, dependem da interação entre os participantes de cada esfera, de suas interpretações e representações.

Seguindo esse viés dialógico, precisamos refletir sobre as implicações pedagógicas da noção de gênero. Na medida em que se considerem os gêneros discursivos como instrumentos para o desenvolvimento da linguagem, é necessário avaliar seu papel no processo de ensino-aprendizagem de línguas, sem perder de vista que o gênero utilizado na escola sempre será a variação do gênero de referência, ou seja, a introdução de um gênero na sala de aula faz dele um gênero didatizado, portanto, uma variante do gênero de origem (SCHNEUWLY \& DOLZ, 1997/2004). Dessa forma, é fundamental a utilização de textos diversos, de variados gêneros, em situações o mais próximas possível de situações reais, buscando sempre alcançar a melhor abordagem para promover as capacidades linguístico-discursivas dos aprendizes. 
Hoje já é consensual que o livro didático deve trazer textos diversificados que possibilitem ao aluno o contato com diferentes gêneros discursivos, mas, além disso, é preciso que os exemplares de gêneros selecionados favoreçam o diálogo com diferentes expressões culturais e a compreensão da pluralidade cultural envolvida no uso da língua, no nosso caso, da língua espanhola, contrastando-a com a cultura do aprendiz. Sabe-se que, “apesar de haver políticas públicas já materializadas em documentos, na prática, o espanhol continua bastante ausente das escolas e se mantém uma crença de que a variante europeia é mais importante que as latino-americanas" (PARAQUETT, 2012:395).

$\mathrm{Na}$ análise de livros didáticos, portanto, julgamos importante observar se a interculturalidade está presente no trabalho proposto com os gêneros discursivos; mais especificamente, se existe diálogo entre culturas falantes do Espanhol, considerando-se não só a Europa, mas também a Hispano-América, através da interação e da construção de conhecimentos.

O que estamos sugerindo como uma proposta de ensino intercultural segue o caminho trilhado por Mendes (2012):

No ensino-aprendizagem de línguas, o sentido que atribuo ao termo intercultural é o de um esforço, uma ação integradora, capaz de suscitar comportamentos e atitudes comprometidos com princípios orientados para o respeito ao outro, às diferenças, à diversidade cultural que caracteriza todo processo de ensino-aprendizagem, seja ele de línguas ou de qualquer outro conteúdo escolar. É o esforço para a busca da interação, da integração e da cooperação entre os indivíduos de diferentes referências culturais (MENDES, 2012:360).

Na mesma direção, documentos oficiais apontam para a relevância de um trabalho pedagógico que valorize o respeito à diversidade linguística e cultural, como preconizam as OCEM:

O fundamental [...], em que pese a impossibilidade de abarcar toda a riqueza linguística e cultural do idioma, é que, a partir do contato com algumas das suas variedades, sejam elas de natureza regional, social, cultural, ou mesmo de gêneros, leve-se o estudante a entender a heterogeneidade que marca todas as culturas, povos, línguas e linguagens (Brasil, 2006:137).

Deste modo, uma perspectiva intercultural, aliada ao esforço de aproximar práticas escolares e práticas sociais, pode ser um caminho teórico-metodológico interessante na busca de abordagens mais adequadas no processo de ensino/aprendizagem de línguas estrangeiras. Ainda segundo Mendes (2012), pensar em uma perspectiva que se propõe intercultural não é apresentar elementos culturais no 
material didático meramente como entretenimento, focalizando-se estereótipos ou conteúdos descontextualizados. O importante, como já discutimos, é selecionar diferentes amostras de linguagem ("textos de variados gêneros, orais e escritos, inclusive os multimodais; imagens e figuras; situações reais de interação etc.”), buscando-se assegurar que os exemplares selecionados sejam representativos das mais diversas situações sociais de uso da linguagem: "cada texto selecionado (em seu sentido amplo) será uma amostra da língua-cultura em foco, em toda a sua potencialidade linguística e cultural” (MENDES, 2012:371).

\section{METODOLOGIA DA PESQUISA}

Para responder às nossas perguntas, adotamos uma metodologia de base qualitativa, que nos permitisse descrever e interpretar o objeto de estudo de forma mais holística, com base no contexto, complexidade e detalhamento dos dados. Utilizando a pesquisa documental, para compor o corpus da investigação, escolhemos os três volumes do livro didático Enlaces: español para jóvenes brasileños, aprovado pelo Programa Nacional do Livro Didático (PNLD), do Ministério da Educação, no ano de 2012.

Ao focalizar a abordagem dos gêneros do discurso nesse material didático, consideramos, dentre os critérios de análise:

- São selecionados exemplares de gêneros discursivos que efetivamente circulam no mundo social? Em que medida as características do gênero de referência são mantidas?

- Que tipos de atividades são propostas em torno da utilização desses gêneros como instrumentos de ensino? De que forma são tratados os elementos socioculturais nessas atividades?

- A seleção de gêneros e atividades propicia a discussão sobre a pluralidade cultural? As questões culturais são exploradas na perspectiva da interculturalidade?

Cumpre ressaltar que nosso interesse não é descrever as características dos gêneros que compõem o livro didático, mas, sim, verificar como a sua dimensão sociocultural é abordada. No presente trabalho, selecionamos apenas uma seção da unidade 1 do primeiro volume, como veremos a seguir.

\section{ANÁLISE DO CORPUS}

Na seção a ser analisada, que tem por objetivo orientar e desenvolver estratégias 
de leitura a partir do trabalho com diversos gêneros discursivos, são propostas atividades diversificadas de compreensão leitora, ampliando a perspectiva reflexiva do tema tratado. Os textos apresentados tratam de assuntos relacionados aos chats (batepapos virtuais) e à questão da identidade na internet. Aparecem três gêneros diferentes: uma crônica (um pequeno fragmento), uma tira cômica e, por fim, um artigo de opinião (adaptado). Os dois primeiros textos são utilizados somente como motivadores para a leitura do terceiro, no caso, o artigo. Não há a proposta de se trabalhar detalhadamente com os alunos a respeito dos dois primeiros gêneros. Para tal afirmação, consideramos tanto as atividades do livro do aluno como as sugestões apresentadas pelo Guia do Professor.

Apresentamos, a seguir, a reprodução dessa seção específica tal como aparece no livro do aluno.

\section{¡Y no sólo esto!}

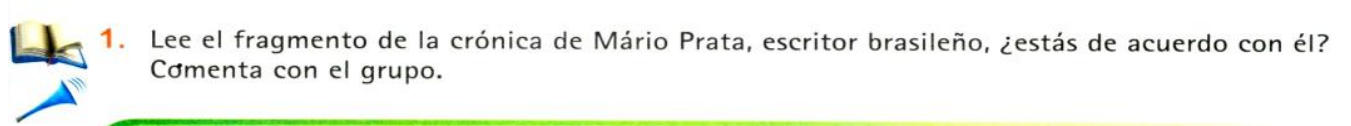

Chat, pra quem não sabe, é um lugar onde fica uma porção de chatos, todos com pseudônimos (homem diz que é mulher e mulher vira homem) a te perguntar: você está aí? Mário Prata, "Chats e chatos pela Internet". O Estado de S. Paulo, 02/12/1998.

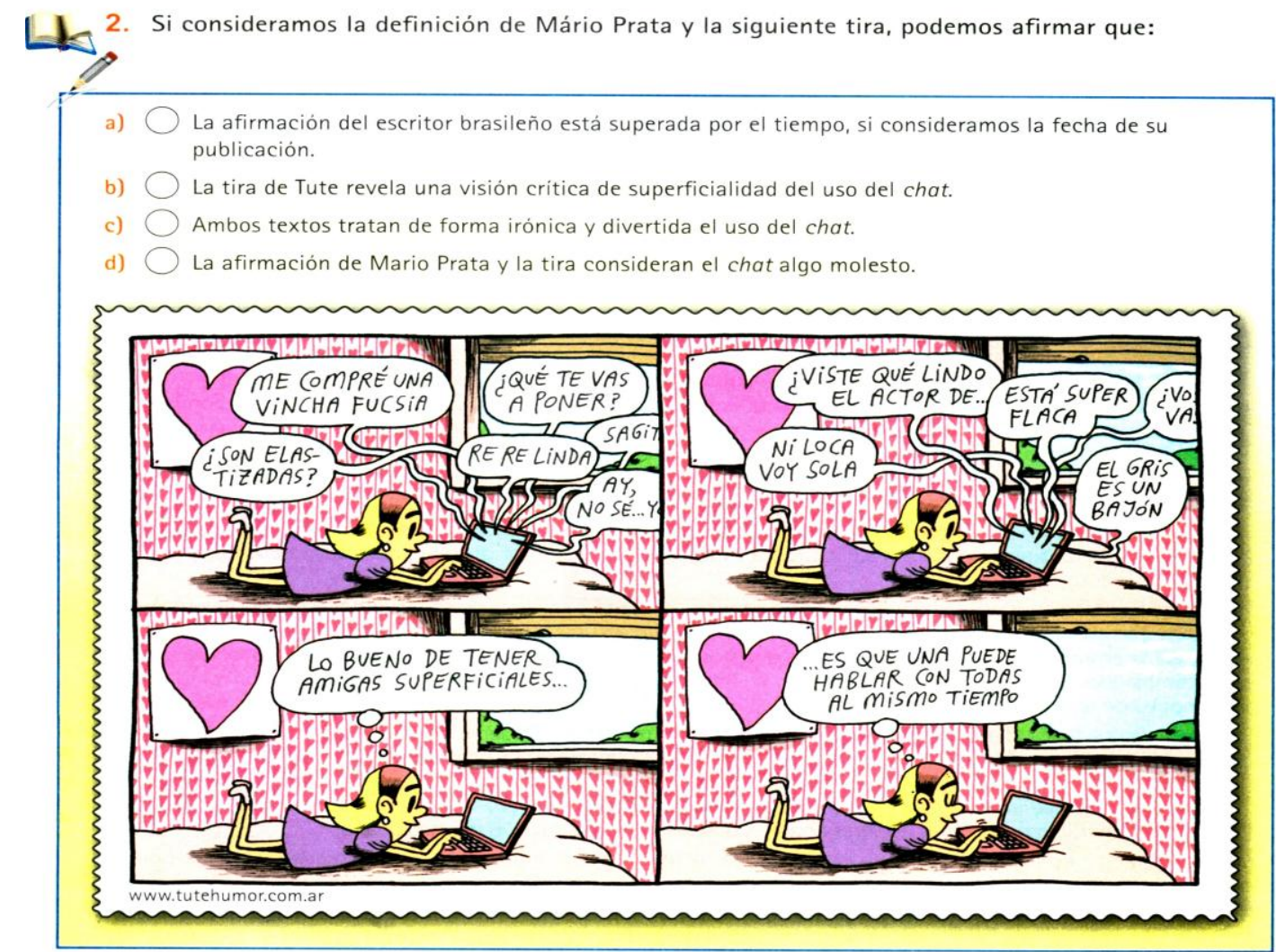

(Extraído de OSMAN, S. et al., 2010a, p. 15). 
. Además de la creación de perfiles falsos, ?qué otros problemas éticos enfrentamos en Internet?

4. Contesta las preguntas marcando Sí o NO, según tu experiencia.

a) ¿Utilizas redes sociales como Facebook, Orkut, Twitter, etc.?

b) ¿Ya has recibido mensajes con perfiles anónimos?

c) ¿Conoces a personas que usan perfiles falsos?

d) ¿Conoces a personas que han sido insultadas en la red?

e) ¿Conoces a personas cuyos nombres, fotos, datos, etc. hayan sido utilizados de manera inadecuada en la red?

5. Lee el fragmento del artículo de Pablo Capurro sobre la impunidad en Internet y subraya las palabras que no conozcas. Luego fijate en el contexto donde aparecen estas las palabras y deduce los posibles significados que pueden tener. Comparta tus hipótesis con un compañero/a. 00

\begin{tabular}{|c|c|c|c|c|c|c|}
\hline El Pais & El Mundo & Cartas de lectores & Sociedad & Ciudad & Policiales & Deportes \\
\hline
\end{tabular}

Internet es un mundo impune

Por: Pablo Capurro

Internet es el medio de comunicación con mayor grado de impunidad entre todos los inventados por el hombre. Desde su nacimiento, la web se convirtió en un centro de operaciones para los que, sin sufrir consecuencia alquna, ensucian la reputación de una persona, insultan al projimo y engañan constantemente. Estos delitos contra la integridad moral de las personas no cesan. Actores de televisión, deportistas, periodistas, empresarios, y también no famosos, son juzgados día a dia en un tribunal repleto de jueces, aunque sin testigos ni pruebas.

Salvo unos pocos sitios que establecen límites y controles para publicar, los sistemas son, en su mayoría, de libre uso y abuso. Las injurias quedan publicadas por toda la vida y Google, promotor de lo bueno y de lo malo que tiene Internet, las indexa en su servicio.

La reputación Google preocupa a cualquiera que conozca el uso que muchas personas dan a esta herramienta y la confianza que ellas le tienen. Googlear un nombre se convirtió en una actividad extendida entre los usuarios de la web, y alli se entremezclan verdades y mentiras que nos cargan de prejuicios sobre las personas. Pero los tiempos están cambiando. Desde que falsear la identidad en Internet se convirtió en un delito, el tema del anonimato comenzó a ser motivo de análisis.

El manejo de una única identidad digital, un registro universal para todos los servicios de la web, despunta como primera opción para intentar resolver este problema. Aunque no fueron creadas con este objetivo, Facebook, Google y Yahool lanzaron herramientas que permiten utilizar servicios de muchas páginas, con nuestro usuario y clave de Facebook, por ejemplo. Esto hace que uno no vuelva a registrarse, a crear otra identidad web, sino que reutilice siempre un mismo registro. Asi, implicitamente, todas nuestras acciones quedan registradas con el mismo usuario.

Otros sugieren el registro y el control de las direcciones IP (Protocolo de Internet). Y aparecen proyectos ambiciosos como el de MylD. is, que busca crear un certificado de identidad digital. El problema despierta grandes diferencias y controversias entre los usuarios, y también entre los estudiosos del mundo digital y de su costado legal. El anonimato, tan natural como dañino, ha entrado en discusión en el on-line. Adaptado de www.clarin.com. Accedido el 24-02-2010

(Extraído de OSMAN, S. et al., 2010a, p. 16). 
6. Contesta las preguntas luego coméntaselas al grupo.

a) ¿Cuál/es son las razones para que las personas utilicen perfiles falsos 0 anónimos 0 usen de manera inadecuada las redes sociales?

b) ¿Conoces situaciones en las que haya habido algún tipo de consecuencia al que ha creado el perfil falso, insultado o utilizado datos e imágenes de manera inadecuada?

7. Vuelve a leer el texto y contesta las preguntas.

a) ¿Qué tipo de personas suelen sufrir delitos morales en internet?

b) ¿Cuáles son los delitos mencionados en el texto contra la integridad moral de las personas?

c) El fragmento del texto "... son juzgados dia a dia en un tribunal repleto de jueces, aunque sin testigos ni pruebas". ¿Cómo se interpretan las palabras tribunal y jueces?

- Tribunal:

- Jueces:

d) El texto afirma que "falsear la identidad en Internet se convirtió en un delito". ¿Cuáles son las posibles soluciones para este problema?

e) Según el texto, la impunidad presente en las relaciones en Internet se debe:

( ) a la existencia de un registro universal para todos los servicios de la web.

( ) a la dificultad de identificar en el mundo digital a los que cometen los delitos.

( ) a Google, que promueve cosas malas también.

f) ¿Cómo definirias la expresión utilizada en el texto "Googlear un nombre"?

g) "El anonimato, tan natural como dañino, ha entrado en discusión en el on-line." Participa de esta discusión y diles a tus compañeros ¿qué propondrias para resolver este problema?

(Extraído de OSMAN, S. et al., 2010a, p. 17).

$\mathrm{Na}$ atividade 1, em que se propõe a leitura do fragmento retirado da crônica (na verdade, uma definição de chat), percebe-se uma proposta dentro da perspectiva dialógica da linguagem através da interlocução que se estabelece entre autor, texto e leitor - ¿Estás de acuerdo con él? (Você está de acordo com ele?). Com esse questionamento, espera-se do aluno-leitor uma resposta ao enunciado produzido, sendo sua posição discutida com o grupo de colegas. Dessa forma, podem-se ter vários enunciados, vários tipos de reação/resposta, numa relação de concordância ou não com o que já foi dito anteriormente. 
A atividade seguinte, na forma como é elaborada, já supõe um diálogo entre o texto 1 e o texto 2 . É interessante destacar, entretanto, a questão da autoria dos textos: a presença de um escritor brasileiro, Mário Prata, e de um humorista gráfico argentino, Juan Matías Loiseau, conhecido como Tute. Observa-se a referência feita à nacionalidade de Mário Prata, porém, não é apresentado nenhum comentário em relação a Tute. Nesse caso, seria interessante comentar também sobre o criador da tira cômica, contextualizar os textos usados para introduzir a seção, tratar minimamente de sua situação de produção, mesmo que não houvesse aprofundamento das particularidades dos gêneros Crônica e Tira Cômica. Como sugestão, seria uma oportunidade para se considerar alguns pontos que remetem a questões interculturais, como, por exemplo: tanto o autor brasileiro quanto o argentino, tratando o tema de forma irônica, trazem visões críticas a respeito dos bate-papos virtuais.

Para ampliar a discussão, poderiam ser direcionados aos alunos outros questionamentos que tocam a questão de identidade cultural, tais como: $o$ comportamento das adolescentes brasileiras se parece com o da garota da tira argentina? Quais são os assuntos tratados pela garota da tira e suas amigas? Vocês (meninas brasileiras) também se interessam por esses assuntos? E os meninos, o que pensam sobre tais assuntos? Pode-se perceber na tira a referência a assuntos diversos, como: tipos de roupa, atores bonitos, preocupações com o corpo, festas, todos bem próximos do universo sociocultural das meninas brasileiras também. A tira apresenta uma adolescente loira, de pele clarinha, com um quarto todo rosa, computador rosa, e que parece estar bastante interessada no bate-papo que acontece no computador. Essa menina da tira poderia ser tanto uma argentina como uma brasileira, uma vez que apresenta gostos e interesses pessoais típicos de adolescentes, independentemente de sua nacionalidade, e características físicas que poderiam ser comuns a habitantes de ambos os países. Vale ressaltar, ainda, a marcante presença do estereótipo do feminino, o que pode ser ilustrado não só pelo conteúdo temático, mas também pela linguagem icônica, com a imagem, por exemplo, do quarto todo decorado com coraçõezinhos cor de rosa. Ao final da tira, no penúltimo balão, a consideração da personagem sobre amizades superficiais ( "Lo bueno de tener amigas superficiales..." ) mereceria atenção maior, embora não tenha sido realizada uma atividade de compreensão do texto mais aprofundada. Como questão sociocultural, valeria discutir o que seria o perfil de um verdadeiro amigo na sociedade contemporânea. Essas reflexões, porém, não são levantadas pelo livro didático. 
É importante que o professor consiga conduzir a discussão nesse sentido, levando os alunos a perceberem o quanto é comum o interesse dos jovens, independentemente do país, pelos chats e redes sociais, o que tem suscitado posicionamentos críticos bem semelhantes entre autores de diferentes nacionalidades. $\mathrm{O}$ enfoque intercultural não é explicitamente trabalhado pelo livro didático aqui, como vimos, por isso essa tarefa caberia ao próprio professor.

A atividade apresentada logo após a leitura dos textos iniciais, comparando-os, favorece uma melhor compreensão do tema que está sendo abordado. Trata-se de um exercício de múltipla escolha bem dentro do padrão de atividades de compreensão de texto em livros didáticos, que não se está aqui avaliando como necessariamente problemáticas, mas que deixam de contemplar aspectos que seriam importantes num material de leitura realmente orientado pela noção de gênero discursivo.

O terceiro e último gênero a ser analisado é um fragmento do artigo de Pablo Capurro sobre a impunidade na internet. $\mathrm{O}$ texto adaptado foi retirado do site

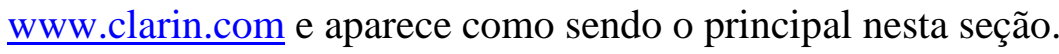

É importante atentar para a seguinte afirmação, trazida pelo Guia do Professor: "Como se trata del primer texto del libro, motive a los alumnos para la primera lectura [...]" (OSMAN, S. et al., 2010b:12). De acordo com a perspectiva bakhtiniana adotada neste estudo, destacamos a impossibilidade de ser considerado o primeiro texto ou, ainda, a primeira leitura. Nessa mesma seção, encontramos dois textos anteriores fragmento de crônica e tira cômica, pertencentes a enquadres de gêneros discursivos diferentes, que apresentam características próprias, diversas daquelas apresentadas em um fragmento de artigo.

De acordo com a sugestão apresentada no Guia do Professor, antes de ser realizada a leitura do artigo, o professor deve chamar a atenção dos alunos para os elementos paratextuais do artigo: formato, desenho, título. E, em seguida, apresentar algumas questões, como:

- De que tipo de gênero se trata?

- Onde costuma ser publicado?

- Quais são as características do autor?

- Com que frequência os alunos leem artigos e por quê?

Observando a proposta apresentada no Guia do Professor, há a preocupação em 
proporcionar ao aluno a possibilidade de identificar particularidades da situação de produção do gênero artigo de opinião e, ainda, em levá-lo a ser capaz de dominar as características específicas desse tipo de texto. De acordo com esse mesmo Guia, tal abordagem do gênero discursivo pretende chamar a atenção para as características próprias do funcionamento de determinados gêneros escritos com o objetivo de auxiliar o aluno na sua reprodução.

A abordagem sugerida no livro didático para o trabalho com o artigo de opinião contempla, em alguma medida, propostas pedagógicas de uso dos gêneros, como na visão apresentada por Lopes-Rossi (2006), que defende que as características discursivas dos gêneros sejam exploradas:

\begin{abstract}
Por "características discursivas" - de uma forma não teoricamente aprofundada, mas possível para a sala de aula e minimamente suficiente para o trabalho pedagógico podemos entender as condições de produção e de circulação de um gênero, de maneira geral reveladas com respostas a indagações do tipo: Quem escreve (em geral), esse gênero discursivo? Com que propósito? Onde? Como? Quando? Com base em que informações? Como o redator obtém as informações? Quem escreveu este texto que estou lendo? Quem lê esse gênero? Por que o faz? Onde o encontra? Que tipo de resposta pode dar ao texto? Que influência pode sofrer devido a essa leitura? Em que condições esse gênero pode ser produzido e pode circular na sociedade? (LOPES-ROSSI, 2006:77).
\end{abstract}

Nas atividades de pré-leitura do artigo, sugere-se que o professor apresente perguntas aos alunos sobre o tema tratado e, logo após, trabalhe conteúdos ou aspectos formais, tais como vocabulário, sugerindo o uso de um dicionário e/ou do glossário que aparece no final do próprio volume. Após a leitura, são propostas atividades diversificadas de compreensão leitora, buscando promover a interação entre os conhecimentos prévios dos alunos e o tema estudado, levando-os a refletirem sobre o mesmo. Há questões que prevêem a releitura do artigo para, então, propor perguntas que pressupõem "a exploração concreta do texto" (OSMAN, S. et al., 2010b:12). Os alunos podem responder às primeiras questões, consideradas "respostas livres", em português e, para as demais, a resposta em língua espanhola deve ser buscada no texto. Se há boas questões de compreensão, percebe-se que a questão ética envolvida na criação de perfis falsos e a questão mais abrangente da identidade digital aparecem, mas não são suficientemente exploradas.

Vale destacar também que não há um trabalho que leve o a aluno a pensar sobre a organização textual do artigo de opinião, sobre a sequência textual dominante (argumentativa), ou que o leve a identificar a tese central. Parece que somente a questão 
g estaria mais próxima desse tipo de abordagem.

Analisando-se a seção ;Y no sólo esto! como um todo, é possível notar que não se privilegia o enfoque intercultural no trabalho com a compreensão leitora, tal como os textos e atividades são apresentados nesta primeira unidade. Embora nem todos os gêneros discursivos apresentados nessa obra necessitem remeter às questões que perpassam esse viés, ou se prestem bem a esse objetivo, acreditamos que um tema tão abrangente e complexo, que aborda questões de identidade, o cuidado com o uso da internet, a impunidade virtual, as redes sociais e os chats, e abre espaço para ricas discussões de cunho social, deveria levar naturalmente a reflexões no campo da interculturalidade.

Como o próprio livro didático não oportuniza esse tipo de reflexão, caberia ao professor realizar esse trabalho, por exemplo, propondo questões que indicassem como é tratada a impunidade virtual em diferentes países, ou discutissem a respeito dos relacionamentos iniciados a partir de chats, que, muitas vezes, envolvem pessoas de culturas totalmente distintas. Tudo isso poderia promover ganhos significativos em um processo de ensino/aprendizagem de línguas que se propõe a formar cidadãos conscientes e críticos em nossa sociedade, como prevêem os documentos oficiais.

\section{PALAVRAS FINAIS}

Para a prática de sala de aula, necessitamos, além do saber pedagógico, estar bem informados teoricamente e refletir sobre qual concepção de língua e de ensino de língua estamos adotando. O livro didático aqui focalizado estaria assumindo, a princípio, um ensino de espanhol/língua estrangeira norteado pela perspectiva dos gêneros e da interculturalidade. Foi possível observar que as autoras do livro tiveram, de fato, o cuidado de selecionar diferentes gêneros para serem trabalhados, o que já representa um grande avanço. No entanto, alguns aspectos poderiam ser revistos para um melhor aproveitamento dos gêneros discursivos como uma ferramenta eficaz pra o processo de ensino/aprendizagem, em particular quando pensamos em um material didático que se propõe, inicialmente, com enfoque intercultural. Cumpre ressaltar que este trabalho não teve por objetivo avaliar a qualidade do livro (mesmo porque isso já foi feito pelo PNLD), mas sim salientar alguns pontos fracos e fortes encontrados no que diz respeito às nossas perguntas específicas de pesquisa, buscando, ainda, apontar/sugerir maneiras de complementar/modificar o que já existe. 
Reforçamos nossa visão de que o uso adequado dos gêneros pode ser um caminho produtivo para o aprendizado de língua e, dessa forma, torna-se importante verificarlhes o potencial para se trabalhar a questão da cultura, podendo-se pensar, ainda, sobre quais gêneros mostram-se mais propícios a uma abordagem intercultural dentre os apresentados pelo livro didático.

Com relação aos resultados e impactos para futuras pesquisas, este estudo pretende fornecer subsídios para a compreensão do trabalho pedagógico com gêneros discursivos na aprendizagem de espanhol/língua estrangeira, atentando, principalmente, para o enfoque intercultural. Pretende também, em última instância, contribuir para a reflexão acerca do papel social e político do professor de línguas na sociedade contemporânea.

\section{REFERÊNCIAS}

BAKHTIN, M. (1979/2010). Estética da criação verbal. Trad. Paulo Bezerra. 5. ed. São Paulo: Martins Fontes.

BRASIL. (2006) Ministério da Educação. Secretaria de Educação Básica. Orientações curriculares para o ensino médio: linguagens, códigos e suas tecnologias 87-164. Brasília: Ministério da Educação/Secretaria de Educação Básica.

(1999a). Ministério da Educação. Secretaria de Educação Média e Tecnológica. Parâmetros curriculares nacionais: ensino médio. Bases legais. Brasília: Ministério da Educação/Secretaria de Educação Média e Tecnológica.

- (1999b). Ministério da Educação. Secretaria de Educação Média e Tecnológica. Parâmetros curriculares nacionais: ensino médio. Linguagens, códigos e suas tecnologias. Brasília: Ministério da Educação/Secretaria de Educação Média e Tecnológica.

. (2002). Ministério da Educação. Secretaria de Educação Média e Tecnológica. PCN+ Ensino Médio: orientações educacionais complementares aos Parâmetros curriculares Nacionais. Linguagens, códigos e suas tecnologias. Brasília: Ministério da Educação/Secretaria de Educação Média e Tecnológica.

FARACO, C. A. (1997). Bakhtin e os discursos enunciativos no Brasil: algumas perspectivas. In: BRAIT, B. (eds.) Bakhtin, dialogismo e construção do sentido 159177. Campinas, SP: Editora da UNICAMP.

FIORIN, J. L. (2008). Introdução ao pensamento de Bakhtin. São Paulo: Ática.

GONZÁLEZ, N. T. M. (2008). A lei 11.161, as Orientações Curriculares e as políticas públicas de formação de professores: a história de um descompasso entre o dizer e o 
fazer. In: $5^{\circ}$ Congresso Brasileiro de Hispanistas. Disponível em: http://addendaetcorrigenda.blogia.com/2008/100201-situacion-actual-de-la-ensenanzadeespanol-en-brasil.php Acesso em: 03 de abr. 2012.

HALL, S. (2006). A identidade cultural na pós-modernidade. Trad. Tomaz Tadeu da Silva, Guaracira Lopes Louro. 11. ed. Rio de Janeiro: DP \& A.

LOPES-ROSSI, M. A. G. (2006). Gêneros discursivos no ensino de leitura e produção de textos. In: KARWOSKI, A. M., GAYDECZKA, B. \& BRITO, K. S. (eds.). Gêneros textuais: reflexões e ensino 73-84. Rio de Janeiro: Lucerna.

MENDES, E. (2012). Aprender a ser e a viver com o outro: materiais didáticos interculturais para o ensino de português LE/L2. In: SCHEYERL, D \& SIQUEIRA, S. (eds). Materiais didáticos para o ensino de línguas na contemporaneidade: Contestações e Proposições 355-378. Salvador: EDUFBA.

(2010). Por que ensinar língua como cultura? In: SANTOS, P \& ALVAREZ, M. L.O. (eds). Língua e cultura no contexto de português língua estrangeira 53-77. Campinas, SP: Pontes Editores.

OSMAN, S. et al. (2010). Enlaces: español para jóvenes brasileños. $2^{a}$ ed. São Paulo: Macmillan.

PARAQUETT, M. (2012). A América Latina e materiais didáticos de espanhol como LE. In: SCHEYERL, D \& SIQUEIRA, S. (eds). Materiais didáticos para o ensino de línguas na contemporaneidade: contestações e proposições 379-304. Salvador: EDUFBA.

SCHNEUWLY, B. \& DOLZ, J. (2004). Gêneros orais e escritos na escola. Trad. de Roxane Rojo e Glaís Sales Cordeiro. Campinas, SP: Mercado de Letras.

\section{AS AUTORAS}

Lucila Carneiro Guadelupe possui graduação em Letras (Português/ Italiano/ Espanhol) pela Universidade Federal de Juiz de Fora (1999), especialização em Desenvolvimento Humano no Contexto da Saúde e Educação (2004) e mestrado em Linguística Aplicada ao Ensino/Aprendizagem de Língua Estrangeira/Espanhol pela Universidade Federal Fluminense (2009). Atualmente é Professora efetiva de espanhol no Colégio de Aplicação João XXIII - UFJF e Doutoranda no Programa de Linguística da UFJF. Tem experiência na área de Letras, com ênfase em Línguas Estrangeiras Modernas, atuando principalmente nos seguintes temas: espanhol/língua estrangeira, gêneros discursivos e interculturalismo. Tem experiência em espanhol para fins específicos.

E-mail: luguadelupe @yahoo.com.br

Marta Cristina da Silva é Doutora em Letras/Estudos Linguísticos pela Universidade Federal Fluminense. Atualmente é Professora Associada do Departamento de Letras Estrangeiras Modernas da Universidade Federal de Juiz de Fora, atuando na área de Língua Inglesa na graduação e na linha de pesquisa Linguística e Ensino de Língua no 
Programa de Pós-Graduação em Linguística. Principais áreas de interesse: gêneros textuais (teorias e transposição didática); livro didático; avaliação; letramentos.

E-mail: martacris.silva@gmail.com 